International Journal of Applied Dental Sciences 2021; 7(3): 169-172

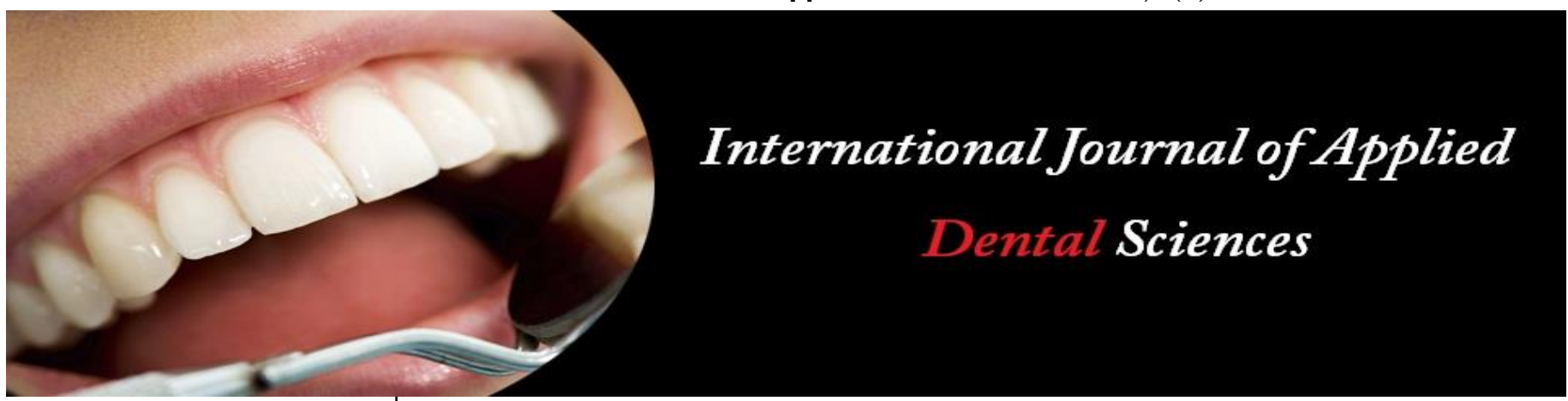

ISSN Print: 2394-7489

ISSN Online: 2394-7497

IJADS 2021; 7(3): 169-172

(C) 2021 IJADS

www.oraljournal.com

Received: 16-05-2021

Accepted: 18-06-2021

Mariana Lizeth Elizondo Alvarado Master in Sciences Student, Universidad Autonoma de Nuevo Leon, Facultad de Odontologia, Monterrey, Nuevo Leon, CP 64460 , Mexico

Arturo Santoy Lozano Professor, Universidad Autonoma de Nuevo Leon, Facultad de Odontologia, Monterrey, Nuevo Leon, CP 64460, Mexico

Arturo Santoy Lozano Associate Professor, Universidad Autonoma de Nuevo Leon, Facultad de Odontologia, Monterrey, Nuevo Leon, CP 64460 Mexico

Rosa Alicia Garcia Jau Professor, Universidad Autonoma de Sinaloa, Facultad de Odontologia, Culiacan, Sinaloa, Mexico

Epigenia Moreno Terrazas Professor, Universidad Autonoma de Sinaloa, Facultad de

Odontologia, Culiacan, Sinaloa, Mexico

Sergio Eduardo Nakagoshi Cepeda Professor, Universidad Autonoma de Nuevo Leon, Facultad de Odontologia, Monterrey, Nuevo Leon, CP 64460, Mexico

Juan Manuel Solis-Soto Professor, Universidad Autonoma de Nuevo Leon, Facultad de Odontologia, Monterrey, Nuevo Leon, CP 64460, Mexico
Corresponding Author:

Mariana Lizeth Elizondo Alvarado Master in Sciences Student, Universidad Autonoma de Nuevo Leon, Facultad de Odontologia, Monterrey, Nuevo Leon, CP 64460 , Mexico

\section{Biodentine: Characteristics and applications today}

\author{
Mariana Lizeth Elizondo Alvarado, Arturo Santoy Lozano, Hugo \\ Villarreal Garza, Rosa Alicia Garcia Jau, Epigenia Moreno Terrazas, \\ Sergio Eduardo Nakagoshi Cepeda and Juan Manuel Solis-Soto
}

DOI: $\underline{\text { https://doi.org/10.22271/oral.2021.v7.i3c.1296 }}$

\section{Abstract}

Introduction: During the last decades, there was a great interest in the development of bioactive dental material with the ability to interact and induce dental tissues. Biodentine is a calcium silicate-based cement that has beneficial effects on pulp cells and promotes the formation of tertiary dentin.

Aim: To analyze the literature on biodentine, as well as its antimicrobial activity, its setting capacity, its clinical applications and its biological properties.

Methodology: Using the keywords biodentine, root canal sealing materials, epidemiology, diagnosis, clinical manifestations, antimicrobial resistance, and treatment, the MEDLINE/PubMed and Science Direct databases were searched, with emphasis on the last 5 years. It was evaluated with the PRISMA and AMSTAR-2 guidelines.

Results: The antimicrobial activity of Biodentine has been greater against strains such as Streptococcus sanguis, Enterococcus faecalis, Escherichia coli and Candida albicans. Biodentine has benefits such as excellent sealability, biocompatibility, good dimensional stability with the advantage of a setting time of 12 to 13 minutes, less than MTA. Materials used in the vital pulp method must have biocompatibility and bioactivity to promote pulp cell activity. Biodentine induces the differentiation of pulp cells into odontoblast-like cells, formation of mineralized tissue and restorative dentin.

Conclusion: The composition and its applications have shown sufficient basis to perform an adequate antimicrobial activity, as well as its setting time improved to 12 minutes. Vital pulp therapy is one of the main uses of this material as it is a widely accepted material for dentin tissues due to its high biological compatibility.

Keywords: biodentine, vital pulp therapy, sealers and pulp capping

\section{Introduction}

Pulp protection therapies aim to maintain the vitality of the tooth in which the pulp tissue has been exposed due to trauma, carious lesions, or restorative procedures ${ }^{[1,2]}$. The emergence of new bioceramic materials, with properties similar to mineral trioxide aggregate-based cements and with improved handling characteristics, suggests the possibility of a clinical alternative ${ }^{[3,4 \text {, }}$ 5]. Recent advances in the field of endodontics have greatly improved the outcome and success rate of dental materials. Over the past three decades, there has been a great interest in the development of bioactive dental material with the ability to interact with and induce the surrounding dental tissues to promote the regeneration of pulpal and periradicular tissues. As these bioactive materials are mainly based on calcium silicates, they are also referred to as calcium silicate materials ${ }^{[6,7]}$. Tricalcium silicate is bioactive and, when hydrated, converts to hydrated calcium silicate. This reacts in the presence of physiological fluids, producing hydroxyapatite, which is biocompatible and induces pulp cell differentiation in the same way as calcium hydroxide ${ }^{[8]}$. In modern dentistry, the field of endodontics has also been improving with the advent of new materials and techniques ${ }^{[9]}$. The term bioactivity is defined as materials that are durable in tissues and have the ability to undergo interfacial changes with surrounding tissues ${ }^{[10]}$. Calcium silicate cements and MTA are used as coating materials. The nanoscale surface composition of these biomaterials is an important variable that determines the host response. The area of the biomaterial in direct contact with DPSCs creates a microenvironment that promotes dentin tissue formation by these stimulated cells. 
Therefore, pulp capping materials must be workable, easy to handle, non-toxic to dental pulp tissues and capable of inducing dentin repair or regeneration ${ }^{[11,12]}$. Biodentine is a tricalcium silicate-based cement that has beneficial effects on dental pulp cells and promotes tertiary dentin formation, while having higher color stability than white MTA ${ }^{[13]}$. Recently, Biodentine, which is a calcium silicate-based material, has gained popularity in endodontics. It has the same clinical applications as MTA, but with superior physicochemical properties, micromechanical anchorage, absence of tooth discoloration, fast setting time and ease of handling ${ }^{[5,14]}$. Modern dentistry offers challenges that lead the practitioner to provide treatments that are a little more conservative than what was usually performed in the past. Currently, there are bioceramic materials available in the market, which allow us to perform root canal treatments as well as vital pulp therapies, with the certainty that we will have an optimal performance and an excellent response in terms of symptomatology. The aim of this article was to analyze the literature about biodentine, as well as its antimicrobial activity, its setting capacity, its clinical applications, and its biological properties.

\section{Methodology}

Information from articles published in PubMed, Science Direct, Springer and EBSCO was analyzed with emphasis on the last 5 years. The quality of the articles was analyzed based on the PRISMA guidelines, i.e., identification, review, choice, and inclusion. The quality of the review was assessed using the measurement instrument for evaluating systemic reviews (AMSTAR-2) ${ }^{[15]}$.

Keywords used were: root canal sealing materials, biodentine, epidemiology, diagnosis, clinical manifestations, antimicrobial resistance, and treatment. The keywords were used individually, as well as each of them related to each other.

\section{Results}

\subsection{Antimicrobial Activity}

Biodentine has bioactive properties, stimulates hard tissue regeneration and did not show an inflammatory pulp response. It also has excellent antibacterial and sealing properties; there is no risk of microleakage, which can cause the pulp to become infected or necrotic. Hard tissue formation due to calcium hydroxide is more of a defense response of the pulp against the irritating nature of the material, whereas materials, such as Biodentine, are compatible with cell recruitment ${ }^{[16]}$. The antimicrobial properties of Biodentine are associated with calcium release and alkalinity. The colloidal gel, formed during cement hydration, leads to the release of calcium hydroxide, which in turn inhibits bacteria. In addition, the $\mathrm{pH}$ of the cement rises to 12.5 during setting, which inhibits bacterial growth and disinfects adjacent areas ${ }^{[17]}$. Biodentine has been used in comparative studies and a vital endodontic repair material possessing several advantageous properties including good sealability, biocompatibility and antibacterial activity. The inherent and persistent alkalinity of Biodentine could be sufficient to control S. mutans ${ }^{[18]}$. root canal flora is polymicrobial and comprises predominantly anaerobic species. The root canal environment is particularly conducive to harboring anaerobic bacteria, which can ferment amino acids and peptides available for their metabolic needs ${ }^{[19]}$. The antimicrobial activity of Biodentine has been significantly higher against certain strains such as Streptococcus sanguis, Enterococcus faecalis, Escherichia coli and Candida albicans, while significantly lower antibacterial activity was observed against Streptococcus mutans and Streptococcus salivarius ${ }^{[20]}$. to other tricalcium silicate-based cements, the cytotoxicity of Biodentine is dose- and time-dependent ${ }^{[21]}$. It has been recently identified that Biodentine has high activity against $\mathrm{E}$. coli and $S$. aureus, moreover, it is significantly higher than the activity presented by MTA ${ }^{[22]}$. Recent studies reveal results where Biodentine has higher antimicrobial activity than MTA [23].

Biodentine is a calcium silicate derivative which has come to modernize dentistry and its requirements in the demand for tissue maintenance. This material has demonstrated significant antimicrobial activity against strains such as $S$. sanguis, E. faecalis, E. coli, C. albicans, which makes it perfect for current use.

\subsection{Setting Capacity}

Researchers have developed a new calcium silicate based active material called Biodentine which claims to have beneficial properties such as excellent sealability, biocompatibility, good dimensional stability with the added advantage of short setting time, improved mechanical strength easy handling and quite economical, thus fulfilling the drawbacks of MTA and hence can be thought to be used as a root filling material ${ }^{[5]}$. The setting time of the material is 12 to 13 minutes, which is significantly less than MTA [21]. Studies have also related the short setting time to the absence of dicalcium silicate in the biodentine composition, which was associated with a slow hydration reaction ${ }^{[24]}$. This rapid setting reaction is attributed to the increase in particle size, the addition of calcium chloride $(\mathrm{CaCl} 2)$ in the liquid component, which decreases the liquid content ${ }^{[25]}$. Biodentine consists of a powder and a liquid. The powder contains mainly tricalcium silicate, dicalcium silicate and calcium carbonate. Zirconium dioxide is a contrast medium. The liquid consists of calcium chloride, which is used as a setting accelerator and water reducing agent in aqueous solution with a polycarboxylate mixture (i.e., a superplast). Mixing is achieved using an amalgamator for 30 seconds at $4000-4200 \mathrm{rpm}$. The initial setting time according to the manufacturer is about $12 \mathrm{~min}{ }^{[26]}$. Biodentine has obtained positive reviews in the literature due to its superior physical properties, better handling, increased biocompatibility and wide range of clinical applications ${ }^{[25]}$. setting reaction of Biodentine is similar to that of MTA and results in the formation of $\mathrm{CSH}$ and $\mathrm{Ca}(\mathrm{OH})^{[10]}$. Biodentine also contains calcium carbonate in the powder, which explains the presence of carbonate phase. The tricalcium silicate grains in Biodentine are finer than MTA and the addition of hydrophilic polymer in the composition facilitates handling [24, 27].

One of the main and most important characteristics of the calcium silicate compound is its improved setting time in its presentation as Biodentine, since, previously, longer setting times were necessary, which did not allow the clinician to finish the treatment in the time required, hence waiting was necessary. The initial setting time, according to the manufacturer, is 12 minutes.

\subsection{Clinical Applications}

A healthy pulp with an uncompromised blood supply at the time of protection is essential for successful vital pulp therapy $[28,29]$. Vital pulp therapies include indirect pulp capping, direct pulp capping, partial (superficial) pulpotomy, and complete (cervical) pulpotomy [30, 31, 32, 33]. Direct pulp 
capping is a method designed to preserve the exposed dental pulp with a protective agent that induces hard tissue repair. Indirect pulp capping refers to the application of a material over a thin layer of dentin where no vital pulp exposure occurs. Pulpotomy differs from pulp capping only in that a portion of the remaining pulp is removed before applying the capping material ${ }^{34]}$. Materials used in the vital pulp method must possess adequate biocompatibility and bioactivity to promote dental pulp stem cell activity and pulp healing in permanent teeth, such are as Biodentine ${ }^{[35]}$. pulp capping has been recommended for primary and permanent teeth [36]. Partial pulpotomy involves removal of two to three millimeters of inflamed pulp to reach healthy tissue and placement of a biocompatible material that provides a tight seal against microleakage. Traditionally, the material of choice was calcium hydroxide $(\mathrm{CH})^{[37]}$. Current guidelines for partial pulpotomy are aimed at immature permanent teeth exposed to trauma ${ }^{[38,39]}$.

Biodentine offers broad compatibility when used in vital pulp treatments, which include indirect pulp capping, direct pulp capping and both partial and complete pulpotomies. The placement of Biodentine is recommended for the induction of a hard tissue barrier in immature permanent teeth exposed to trauma.

\subsection{Biological Properties}

Biodentine is a highly biocompatible non-cytotoxic material $[40,41,42]$. Preservation of the patient's own teeth, even in a difficult situation, is nowadays preferable to surgical intervention and therefore promotes the development of suitable dental repair materials. Biodentine, a mineral trioxide aggregate substitute has been used to replace dentin in a bioactive and biocompatible manner in both the dental crown and root ${ }^{[43]}$. The amount of $\mathrm{Ca} 2+$ released by Biodentine and the depth of $\mathrm{Ca} 2+$ incorporation into root canal dentin are greater than those of MTA [44]. Biodentine induces the differentiation of pulp cells into odontoblast-like cells, in addition to the formation of mineralized tissue and reparative dentin ${ }^{[45,46]}$. It has the ability to interact with dentin, forming a mineralized interfacial zone, with label-like structures extending into the dentinal tubules ${ }^{[47,48,49]}$.

Biodentine is a material widely accepted by dentin tissues due to its high biological compatibility. Over the years and with the use of the added trioxide mineral, components were added to improve its formula in order to obtain better results in dental preservation treatments.

\section{Conclusions}

Biodentine is a material that has demonstrated significant antimicrobial activity against strains such as $S$. sanguis, $E$. faecalis, E. coli, C. albicans, which makes it perfect for its current use. One of the main and most important characteristics of the calcium silicate composite is its improved setting time. Previously, setting times of up to 12 hours were required; at present, only 12 minutes are reported by commercial companies. The most relevant applications of this material include vital pulp therapy such as direct and indirect pulp capping, as well as partial and complete pulpotomies. Biodentine is a material widely accepted by dentin tissues due to its high biological compatibility. Over the years and with the use of the added trioxide mineral, components were added to improve its formula.

\section{References}

1. Hegde S, Sowmya B, Mathew S, Bhandi SH, Nagaraja S,
Dinesh K. Clinical evaluation of mineral trioxide aggregate and biodentine as direct pulp capping agents in carious teeth. J. Conserv. Dent. 2017;20:91-95.

2. Linu S, Lekshmi MS, Varunkumar VS, Sam Joseph VG. Treatment Outcome Following Direct Pulp Capping Using Bioceramic Materials in Mature Permanent Teeth with Carious Exposure: A Pilot Retrospective Study. J Endod. 2017;43(10):1635-1639.

3. Kim J, Song YS, Min KS, Kim SH, Koh JT, Lee BN et al. Evaluation of reparative dentin formation of ProRoot MTA, Biodentine and Bio Aggregate using micro-CT and immunohistochemistry. Restor Dent Endod. 2016;41(1):29-36.

4. Martens L, Rajasekharan S, Cauwels R. Pulp management after traumatic injuries with a tricalcium silicate-based cement (Biodentine): a report of two cases, up to 48 months follow-up. Eur Arch Paediatr Dent. 2015;16(6):491-496.

5. Rajasekharan S, Martens LC, Cauwels RG, Verbeeck RM. Biodentine material characteristics and clinical applications: a review of the literature. Eur Arch Paediatr Dent 2014;15:147-158.

6. Zafar K, Jamal S, Ghafoor R. Bio-active cementsMineral Trioxide Aggregate based calcium silicate materials: A narrative review. J Pak Med Assoc. 2020;70(3):497-504.

7. Cuadros-Fernández C, Lorente Rodríguez AI, SáezMartínez S, García-Binimelis J, About I, Mercadé M. Short-term treatment outcome of pulpotomies in primary molars using mineral trioxide aggregate and Biodentine: a randomized clinical trial. Clin Oral Investig. 2016;20(7):1639-1645.

8. Camilleri J, Sorrentino F, Damidot D. Investigation of the hydration and bioactivity of radiopacified tricalcium silicate cement, Biodentine and MTA Angelus. Dent Mater 2013;29(5):580-593.

9. Raghavendra SS, Jadhav GR, Gathani KM, Kotadia P. Bioceramics in endodontics - a review. J Istanb Univ Fac Dent 2017;51:S128-S37.

10. Debelian G, Trope M. The use of premixed bioceramic materials in endodontics. G Ital Endod 2016;30:70-80.

11. Yu F, Dong Y, Yang YW, Lin PT, Yu HH, Sun X, et al. Effect of an Experimental Direct Pulp-capping Material on the Properties and Osteogenic Differentiation of Human Dental Pulp Stem Cells. Sci Rep. 2016:4;6:34713.

12. Han L, Kodama S, Okiji T. Evaluation of calciumreleasing and apatite- forming abilities of fast-setting calcium silicate-based endodontic materials. Int Endod J. 2015;48:124-130.

13. Vallés M, Roig M, Duran-Sindreu F, Martínez S, Mercadé M. Color Stability of Teeth Restored with Biodentine: A 6-month In Vitro Study. J Endod. 2015;41(7):1157-1160.

14. Hashem D, Mannocci F, Patel S, Manoharan A, Brown JE, Watson TF et al. Clinical and radiographic assessment of the efficacy of calcium silicate indirect pulp capping: a randomized controlled clinical trial. J Dent Res 2015;94(4):562-568.

15. Shea BJ, Reeves BC, Wells G, Thuku M, Hamel C, Moran J et al. AMSTAR 2: a critical appraisal tool for systematic reviews that include randomised or nonrandomised studies of healthcare interventions, or both. BMJ 2017;358:j4008.

16. Shayegan A, Jurysta C, Atash R, Petein M, Abbeele AV. 
Biodentine used as a pulp-capping agent in primary pig teeth. Pediatr Dent 2012;34:e202-8.

17. Chopra MS, Gulve MN. Evaluation of the Antibacterial and Antifungal Activity of Three Retrograde Filling Materials: An In Vitro Study. Int J Cont Med Res. 2016;3:2286-88.

18. Zayed MM, Hassan RE, Riad MI. Evaluation of the antibacterial efficacy of different bioactive lining and pulp capping agents 2015;12:132-139.

19. Bohora A, Kokate S. Concept of probiotics in endodontics. Int J Adv Res 2016;4:1137-42.

20. Özyürek T, Demiryürek EÖ. Comparison of the antimicrobial activity of direct pulp-capping materials: Mineral trioxide aggregate-Angelus and Biodentine. $\mathrm{J}$ Conserv Dent 2016;19(6):569-572.

21. Rajasekharan S, Martens LC, Cauwels RGEC, Anthonappa RP, Verbeeck RMH. Correction to: Biodentine material characteristics and clinical applications: a 3 year literature review and update. Eur Arch Paediatr Dent. 2018;19:129.

22. Ceci M, Beltrami R, Chiesa M, Colombo M, Poggio C. Biological and chemical-physical properties of root-end filling materials: A comparative study. J Conserv Dent. 2015;18:94-99.

23. Bhavana V, Chaitanya KP, Gandi P, Patil J, Dola B, Reddy RB. Evaluation of antibacterial and antifungal activity of new calcium-based cement (Biodentine) compared to MTA and glass ionomer cement. J Conserv Dent 2015;18(1):44-46.

24. Darvell BW, Wu RC. "MTA"-an Hydraulic Silicate Cement: review update and setting reaction. Dent Mater. 2011;27(5):407-422.

25. Malkondu Ö, Karapinar Kazandag M, Kazazoglu E. A review on Biodentine, a contemporary dentine replacement and repair material. BioMed Res Int. 2014;2014:160951.

26. Kaup M, Schäfer E, Dammaschke T. An in vitro study of different material properties of Biodentine compared to ProRoot MTA. Head Face Med 2015;2;11-16.

27. Katge FA, Patil DP. Comparative analysis of 2 calcium silicate -based cements (Biodentine and mineral trioxide aggregate) as direct pulp-capping agent in young permanente molars: a split mouth study. J Endod. 2017;43:507-513.

28. Asgary S, Eghbal MJ, Fazlyab M, Baghban AA, Ghoddusi J. Five-year results of vital pulp therapy in permanent molars with irreversible pulpitis: a noninferiority multicenter randomized clinical trial. Clin Oral Investig. 2015;19(2):335-341.

29. Kundzina R, Stangvaltaite L, Eriksen HM, Kerosuo E. Capping carious exposures in adults: a randomized controlled trial investigating mineral trioxide aggregate versus calcium hydroxide. Int Endod J 2017;50:924-932.

30. Opal S, Garg S, Dhindsa A, Taluja T. Minimally invasive clinical approach in indirect pulp therapy and healing of deep carious lesions. J Clin Pediatr Dent. 2014;38(3):185-192.

31. Akhlaghi N, Khademi A. Outcomes of vital pulp therapy in permanent teeth with different medicaments based on review of the literature. Dent Res J 2015;12(5):406-417.

32. Komabayashi T, Zhu Q, Eberhart R, Imai Y. Current status of direct pulp-capping materials for permanent teeth. Dent Mater J. 2016;35(1):1-12

33. Saghiri MA, Asatourian A, Garcia-Godoy F, Sheibani N. Effect of biomaterials on angiogenesis during vital pulp therapy. Dent Mater J 2016;35(5):701-709.

34. Miyashita H, Worthington HV, Qualtrough A, Plasschaert A. Pulp management for caries in adults: maintaining pulp vitality. Cochrane Database Syst Rev. 2007;(2):CD004484.

35. Gandolfi MG, Spagnuolo G, Siboni F, Procino A, Rivieccio V, Pelliccioni GA et al. Calcium silicate/calcium phosphate biphasic cements for vital pulp therapy: chemical-physical properties and human pulp cells response. Clin Oral Investig 2015;19(8):2075-2089.

36. Ghoddusi J, Forghani M, Parisay I. New approaches in vital pulp therapy in permanent teeth. Iran Endod J. 2014;9(1):15-22.

37. Çalışkan MK, Güneri P. Prognostic factors in direct pulp capping with mineral trioxide aggregate or calcium hydroxide: 2- to 6-year follow-up. Clin Oral Investig. 2017;21(1):357-367.

38. Guideline on Pulp Therapy for Primary and Immature Permanent Teeth. Pediatr Dent 2016;38(6):280-288.

39. Camilleri J. Staining Potential of Neo MTA Plus, MTA Plus, and Biodentine Used for Pulpotomy Procedures. J Endod 2015;41(7):1139-1145.

40. Jang YE, Lee BN, Koh JT, Park YJ, Joo NE, Chang HS, et al. Cytotoxicity and physical properties of tricalcium silicate-based endodontic materials. Restor Dent Endod. 2014;39(2):89-94.

41. Attik GN, Villat C, Hallay F, Pradelle-Plasse N, Bonnet $\mathrm{H}$, Moreau $\mathrm{K}$, et al. In vitro biocompatibility of a dentine substitute cement on human MG63 osteoblasts cells: Biodentine versus MTA. Int Endod J 2014;47(12):11331141.

42. Jung S, Mielert J, Kleinheinz J, Dammaschke T. Human oral cells' response to different endodontic restorative materials: an in vitro study. Head Face Med. 2014;23(10):55.

43. Nikfarjam F, Beyer K, König A, Hofmann M, Butting M, Valesky E et al. Influence of Biodentine - A Dentine Substitute - On Collagen Type I Synthesis in Pulp Fibroblasts in vitro. PLoS One 2016;11(12):e0167633.

44. Han L, Okiji T. Uptake of calcium and silicon released from calcium silicate- based endodontic materials into root canal dentine. Int Endod J 2011;44:1081-1087.

45. Zanini M, Sautier J, Berdal A, Simon S. Biodentine induces immortalized murine pulp cell differentiation into odontoblast-like cells and stimulates biomineralization. J Endod 2012;38:1220-1226.

46. Jung JY, Woo SM, Lee BN, Koh JT, Nör JE, Hwang YC. Effect of Biodentine and Bioaggregate on odontoblastic differentiation via mitogenactivated protein kinase pathway in human dental pulp cells. Int Endod J. 2015;48:177-184.

47. Atmeh AR, Chong EZ, Richard G, Festy F, Watson TF. Dentin-cement interfacial interaction: calcium silicates and polyalkenoates. J Dent Res 2012;91:454-459.

48. Kim JR, Nosrat A, Fouad AF. Interfacial characteristics of Biodentine and MTA with dentine in simulated body fluid. J Dent. 2015;43:241-247.

49. Parinyaprom N, Nirunsittirat A, Chuveera $\mathrm{P}, \mathrm{Na}$ Lampang S, Srisuwan T, Sastraruji T et al. Outcomes of Direct Pulp Capping by Using Either ProRoot Mineral Trioxide Aggregate or Biodentine in Permanent Teeth with Carious Pulp Exposure in 6- to 18-Year-Old Patients: A Randomized Controlled Trial. J Endod. 2018;44(3):341-348. 